\title{
The Influence of Inflexible Work Schedules and Land Use Design on Traffic Congestion in Kigali City.
}

\author{
Lea Bagenzi ${ }^{1}$, Taslim Alade ${ }^{2}$, Sylion Muramira ${ }^{3}$ \\ ${ }^{1}$ Institute of housing and urban development studies (IHS), Erasmus University Rotterdam \\ ${ }^{2}$ Erasmus Graduate School of Social Sciences and the Humanities, Erasmus University Rotterdam. \\ ${ }^{3}$ School of Engineering, College of Science and Technology, University of Rwanda \\ *Corresponding Author: bagenzilea196@gmail.com \\ DOI: $10.4314 /$ rjeste.v4i1.12 \\ https://dx.doi.org/10.4314/rjeste.v4i1.12
}

\begin{abstract}
Travel demand is still poorly managed in Kigali city. The other research that was done on traffic congestion in Kigali city aimed to regulate the supply side of the problem. However, this study aims to regulate the demand side of traffic congestion on Kimironko- CBD, Nyanza KicukiroCBD, and Gisozi- CBD roads in Kigali city where inflexibility of work schedules and land use design were presented as the main issues leading to traffic congestion. The statistical results of the study did not show any strong correlation between the independent variables and the dependent variables because of the limited number of respondents that undermined the relationships and the questionnaire data collected represented peak-period only hence social-economic variables did not show any relationship with travel time as proved by other empirical studies. However, using the data from interviews, questionnaires, ArcGIS Pro, and secondary data, the study shows that there is a significant relationship between inflexible work schedules, land use design, and traffic congestion where departure time choice, commuting distance, land use mix, and connectivity has influenced significantly travel time and level of service. All the 3 roads under study are congested where Gisozi-CBD road is the most congested and Kicukiro-CBD road is the least congested.
\end{abstract}


Rwanda Journal of Engineering, Science, Technology and Environment, Volume 4, Issue 1, June 2021

eISSN: 2617-233X | print ISSN: 2617-2321

This study supports the view that traffic congestion can not only be regulated by focusing on the supply side of traffic congestion but balancing both the demand and supply side of the problem. However, travel demand management that aims to reduce unnecessary trips is the pillar to achieve sustainable mobility which focuses on the movement of people and goods rather than the movement of cars.

Keywords: Inflexible work schedules. Land use design. Traffic congestion. Travel demand management.

\section{Introduction}

Transport is the main sector that plays a significant role in the development of the country economically. For transport to become sustainable, it must ease mobility, accessibility, and above all being affordable (World Bank Group, 2018). Balancing the three pillars of sustainability in transport is a challenge where more attention is paid to economic sustainability only. Daniel et al., (2010) discussed that transport contributes $13 \%$ of global greenhouse gases and $23 \%$ of $\mathrm{CO}_{2}$ emissions globally. It is expected that the $\mathrm{CO}_{2}$ emitted by the transport sector globally will increase by up to $53 \%$ by 2030 . This is a challenge resulting from traffic congestion especially in cities experiencing rapid urbanization and population growth. Nowadays, $55 \%$ of people live in an urban area which is expected to reach $68 \%$ in 2050 (John, 2019).

Rwanda as a rapid urbanization country also faces different transportation challenges the Road transport is the main type of urban transport for passengers and goods in the country with a road density of $0.53 \mathrm{~km} / \mathrm{km}^{2}$ (Ministry of Infrastructure, 2008). The main challenge of urban road transport in Rwanda is population growth and an increase in private car ownership. Kigali city, the capital city located at the center of the country is growing rapidly because of immigration and its economic growth (Leopold \& Aloys, 2018). It is estimated that the population of Kigali city increase by $4 \%$ every year and it is unavoidable. Moreover, private car ownership in the city is increasing drastically (Jean Chrétien, 2017). This can be underscored by poor organization and integration of public transport in Kigali city where long queues of people waiting for buses become a daily challenge. This discourages people to use public transport where many decide to use motorcycles or buy their cars. In 2014, the Mayor of Kigali said that the long waiting queues of 
Rwanda Journal of Engineering, Science, Technology and Environment, Volume 4, Issue 1, June 2021

eISSN: 2617-233X | print ISSN: 2617-2321

buses will be resolved at the end of the year, but even nowadays the never-ending queues are still there especially during rush hours (Observers, 2015).

Flexible working hours allow employees to work in shifts which reduce the number of workers going and coming from work during peak hours (Hirshfield, 2019). According to Omondi, (2018) flexible working schedules are observed as the ones that allow the employees to choose when to work and the place where the job should be done outside the temporal workplace. Inflexible working schedules that do not allow people to choose when and where to work have proven as the environmental, economic, and social hinder of sustainability (Lundqvist, 2003). Leopold and Aloys (2018) highlighted that workers in Kigali city contribute a lot to traffic congestion in the city because more than 70\% of workers start working from 7:00 A.M- 8:00 A.M and end their work at 5: 00 P.M. This applies to government, private, banking, and commercial workers. The majority of workers work from Monday to Friday except for shopping centers that sometimes open at the weekend. Additionally, because many people start and end their work at the same time, traffic congestion is inevitable during peak periods or rush hour.

Mixed land use concept was proved by many researchers like (Frank, 2006; Meerkerk, 2015) using empirical studies that it contributes to the sustainability of cities. All compatible activities being close to each other reduce the travel time and promote walking and cycling in neighbourhoods (Jabareen, 2006). Centrally planned cities have seen as the urban forms that increase traffic congestion through increasing travel time and commuting distance (Meerkerk, 2015).According to Janssen, (2017) separation of workplaces and residential areas increase commuting distance of workers who commute every day at the same time and went to the same place every day. This issue of higher commuting distance can be better explained by both inflexible working schedules and lack of mixed land use plans in Kigali city which does not allows workers to change when and where to work. Kigali city hosts the most administrative functions in Rwanda where the city is considered as centrally planned which means that workers moved in the city Centre and out of the city center at the same time.

Connectivity is another land use design that promotes sustainable transport. The ease of moving from one place to another has proven to reduce travel distance and time. Road connectivity is one of the essential aspects of designing neighbourhoods (Stangl \& Guinn, 2011). Physical conditions 
of the roads and number of intersections can either reduce or increase travel time. Same as land use mix, connectivity also can promote the use of non-motorized means of transport (Saelens, Sallis, \& Frank, 2003). Neighbourhoods with integrated street networks have proven to have a low level of traffic congestion during the peak period. The other challenge identified by Leopold (2018) is that the majority of paved roads in Kigali city are in poor conditions because of poor maintenance hence need rehabilitation. Kigali city has over $1000 \mathrm{Km}$ of roads where only $153 \mathrm{Km}$ are paved roads. This implies that $85 \%$ of the roads in Kigali city are not in conditions to boost the economic condition of the country (Jean Chrétien, 2017). One of the examples is NyabugogoGatsata road that was planned to be expanded by 2 double lanes network, but the project only added pedestrian's walkway and some other repair. The road was supposed to reduce traffic congestion in that area, but traders still complain that the road does not meet their daily practices (Dan, 2017). This indicates that there is connectivity problem in Kigali city where roads are not in good physical conditions and the width and length of the road are not enough to cope with the number of vehicles using the roads. From the above problem statement, there is a need to address the demand side of traffic congestion in Kigali city by regulating and reducing travel needs. It is in this outlook a study aimed to provide knowledge that will be beneficial in regulating the demand side of traffic congestion in Kigali city by explaining how inflexible work schedules and land use design influence traffic congestion was conducted on Kimironko- CBD, Nyanza Kicukiro- CBD, and Gisozi- CBD roads in Kigali city.

This research has three main contributions. The first is the analysis of relationship between inflexible work schedules and land use design, as related to traffic congestion. Second is the unraveling of congestion from the spatial angle as related to land-use and connectivity, using GIS. Third is the understanding of level of service as a supply side of transport infrastructure and how it influences travel time and road congestion.

\section{Material and Methods}

\subsection{Methodology}

Different researchers mix quantitative and qualitative information to explain how land use design and inflexible work schedules influence traffic congestion because it was proven empirically that 
quantitative correlation between those variables is not enough to explain these hypotheses (Ferguson, 2016; Lundqvist, 2003; Parthasarathi, Levinson, \& Hochmair, 2013). In this research mixed method was adopted where both quantitative and qualitative data was collected.

Quantitative data was collected using closed-ended questionnaires and open-source data of geographic information systems, using ArcGIS pro while qualitative data was collected through semi-structured interviews and closed-ended questionnaires. The triangulation with information obtained from questionnaires and interviews was possible since ArcGIS and secondary data was used in certain features.

Qualitative data was collected through questionnaires and semi-structured interviews with selected professionals who work in planning, transport, and ministry of workers in Kigali city. The interview questions were formulated based on the indicators selected on each variable and the research questions of this study. Interviewing professionals who are in charge of transport, workers, and urban planning in Kigali city was useful because more knowledge was gained to support information from questionnaires, secondary data, and spatial analysis.

\subsection{Research process}

Using ArcGIS software, Kernel density was performed to find the availability of 4-way and 3-way intersections of each road. Using the open street maps, Physical characteristics of the roads were obtained. Additionally, using Kigali city master plan, information about land use mix indicators like presence of shops, hospitals, schools, and offices within residential area were collected. Moreover, distance and off-peak period travel time and from one place to another were obtained using secondary data source which is Google maps.

Closed ended questionnaires was used to collect data from 3 neighbourhoods that connect the 3 selected roads in Kigali city to the CBD. Door to door method was used to get information from workers who live in Kimironko, Gatenga and Gisozi neighbourhoods. Online digital questionnaires formed using Qualtrics survey was used where responses were recorded automatically on my project platform. Respondents was selected using stratified random sampling where the $3^{\text {rd }}$ house from each street was selected. The data collected was classified as nominal and ordinal data where SPSS software was used to analyse quantitative data. 
Finally, online-based semi-structured interviews was conducted using zoom and skype. People from various profiles were selected to crosscut different answers. Open ended questions were used for a variety of respondents from MININFRA (Ministry of infrastructure), urban planners, civil engineers, Ministry of public service and labour (MIFOTRA) as well as academics. Interview questions were developed to gain insight into the relationship between land use design, inflexible work schedules and traffic congestion in Kigali city.

\subsection{Time and location}

The data collection process was done in a period of one month from June to July 2020. However, during that time Kigali city was in lockdown due to COVID 19 which did not facilitate the process. The study area is located in Rwanda, precisely, Kigali the capital city. The study focuses only on 3 primary roads connecting residential areas and CBD. Those roads include Kimironko- CBD, Nyanza, kicukiro- CBD, and Gisozi- CBD and residential areas that were considered are limited to Kimironko, Gatenga and Gisozi neighborhoods. Additionally, only working trips from the three neighborhoods were considered. The study area was delineated using ArcGIS Pro. The 3 main roads were digitized and the buffer of $2 \mathrm{~km}$ on each road was applied by assuming that the approximate respondents' geographical home location of the 3 road users live within $2 \mathrm{~km}$ of those roads. The location of the study area is illustrated in the map below. 


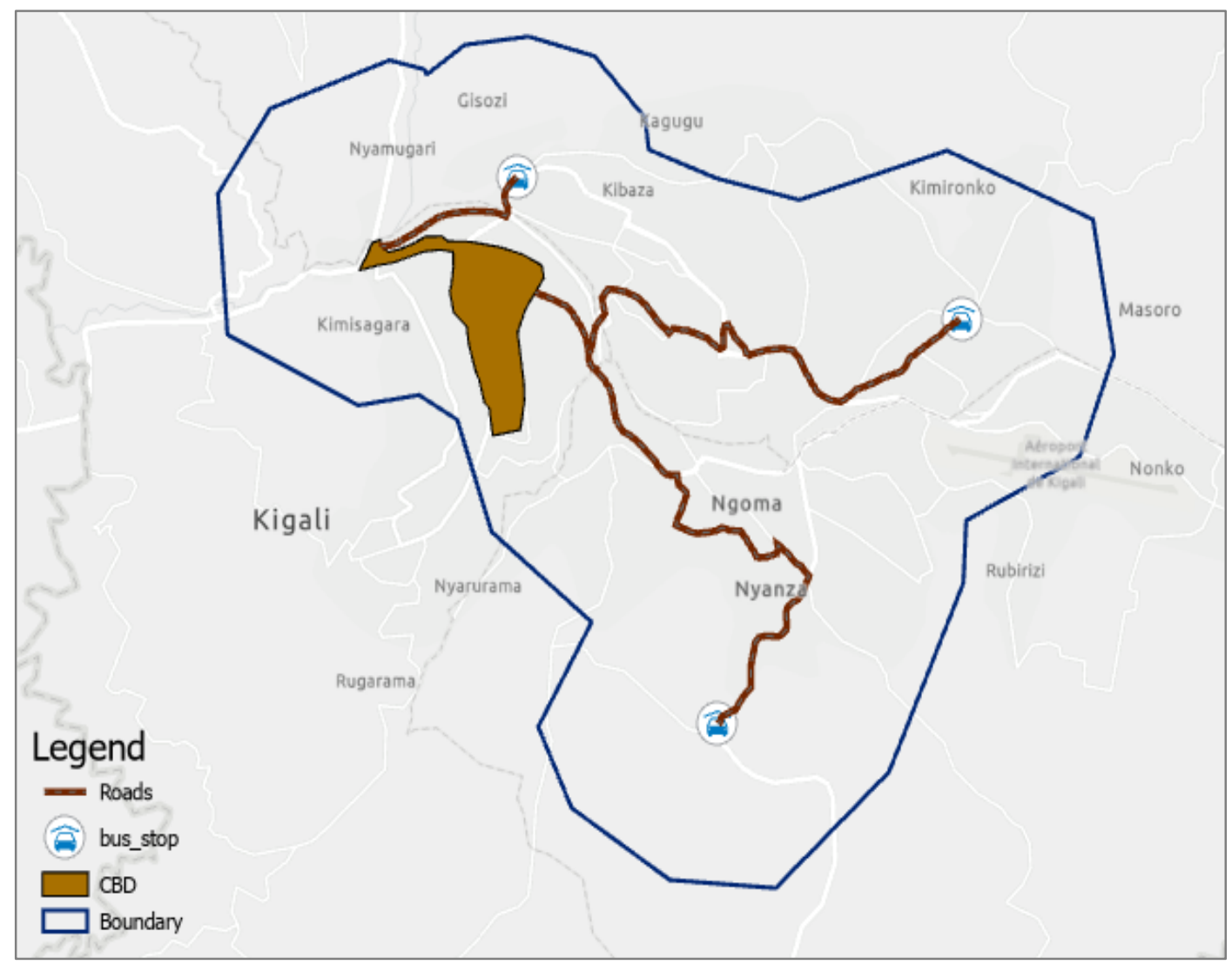

Figure 1: Study area

\section{Analysis and Results}

\subsection{Inflexible work schedules}

This variable has 2 sub-variables namely departure time choice and commuting distance.

\section{Departure time}

Based on 7/11 interviews, traffic congestion starts from 6 A.M up to 9 A.M because most workers start their job from 7 A.M. However, the other 4/11 interviews mentioned that workers prefer to start their journey early at 5 A.M. R1 mentioned that many workers start moving early because they want to be at their working place early regardless of their starting period of the job. $6 / 11$ interviews mentioned that workers start moving immediately after closing jobs whereas 5/11 stated that workers start going back home some minutes after closing jobs. Peak hours were also 
estimated based on the survey results where $47.83 \%$ of respondents start their work at 7 A.M and $43.48 \%$ of the respondents start their work at 8 A.M. $59.01 \%$ of workers end their work at 5 P.M.

A secondary data review on working hours in Rwanda and holidays stated that government workers start work from 7:00 A.M up to 5 P.M whereas the private sector starts their work at 8:00 A.M and ends their work at 5 P.M. both government and private sector have 1-hour lunch break. The source also added that banking hour is from 8:00 A.M up to 5 P.M and shopping hours are from 8:00 A.M up to 6:00 P.M (Fortune of Africa, 2014).

According to Article 49 of the labor code in Rwanda, employees are supposed to work 45 hours per week. This means from 7:00 A.M up to 5:00 P.M with 1-hour lunch break every Monday to Friday (Republic of Rwanda, 2009). The law states that the worker may work overtime based on mutual agreement between parties involved.

In Rwanda almost all workers move in the peak period. Even if the starting period for the private and government sector differ, it is only one hour different which is not enough to say that we have flexibility in terms of choosing the departure time for work. The data from questionnaires were not analyzed based on each neighborhood because the labor law applies everywhere in the country, and they are the same. Additionally, the analysis of the data per each Neighborhood did not show any difference in responses.

To sum up this indicator of time per peak period in Kigali city, it is evident that there is the inflexibility of work schedules in Kigali city because work schedules of workers are clustered in the same period which means that workers do not have the opportunity to work in shifts rather than the designed hours. Based on the findings from interviews, questionnaires and secondary data, rush hour or peak period on Kimironko- CBD, Nyanza Kicukiro- CBD, and Gisozi- CBD roads in Kigali city can be categorized from Monday to Friday as follow:

\section{Table 1: Time per peak period in Kigali city}

\begin{tabular}{|l|l|}
\hline Time of the day & Peak period \\
\hline Morning & 6:00 A.M-9:00 A.M \\
\hline Evening & 5:00 P.M-9:00 P.M \\
\hline
\end{tabular}




\section{Availability of Alternative work schedules}

One respondent out of the 3 respondents that I intended to interview about the availability of alternative work schedules in Rwanda stated that in Rwanda telecommuting or working from home was not common until COVID 19. R11 also added that only private workers can change their start and end period of their work because public workers must follow labour laws that do not allow them to work from home or any other place which is not their office unless they are on the field. The table 2 summarizes the findings from questionnaires for the entire study area where workers were asked whether or not they change the start or end period of their work, whether they change the location of workplaces or whether they telecommute. The purpose of those questions was to know whether there is flexibility or not in the work schedules of Kigali city workers. The responses are grounded on the working conditions of workers before COVID 19.

Table 2: Survey Results: Questions on availability of alternative work schedules.

\begin{tabular}{|c|c|c|c|c|}
\hline & Questions & $\begin{array}{l}\text { Summary of } \\
\text { responses }\end{array}$ & Frequency & Percentage \\
\hline \multicolumn{5}{|c|}{ Flexibility in workplace location } \\
\hline \multirow[t]{2}{*}{1} & \multirow{2}{*}{$\begin{array}{l}\text { Do you change the location of } \\
\text { workplace in a week? }\end{array}$} & Yes & 27 & $16.77 \%$ \\
\hline & & No & 134 & $83.3 \%$ \\
\hline \multicolumn{5}{|c|}{ Flexibility in starting work } \\
\hline \multirow[t]{2}{*}{2} & \multirow{2}{*}{$\begin{array}{l}\text { Do you change the Start period } \\
\text { of your work in a week? }\end{array}$} & Yes & 32 & $19.87 \%$ \\
\hline & & No & 129 & $80.13 \%$ \\
\hline \multicolumn{5}{|c|}{ Flexibility in closing of work } \\
\hline \multirow[t]{2}{*}{3} & \multirow{2}{*}{$\begin{array}{l}\text { Do you change the end period } \\
\text { of your work in a week? }\end{array}$} & Yes & 31 & $19.25 \%$ \\
\hline & & No & 130 & $80.75 \%$ \\
\hline \multicolumn{5}{|c|}{ Telecommuting availability } \\
\hline \multirow[t]{2}{*}{4} & \multirow{2}{*}{$\begin{array}{l}\text { Do you telecommute (work } \\
\text { from home) in a week? }\end{array}$} & Yes & 9 & $5.59 \%$ \\
\hline & & No & 152 & $94.41 \%$ \\
\hline
\end{tabular}

Total number of respondents $=161$ 
Rwanda Journal of Engineering, Science, Technology and Environment, Volume 4, Issue 1, June 2021

eISSN: 2617-233X | print ISSN: 2617-2321

$\mathrm{Yu}$ et al., (2019) Stated that by introducing flexible work schedules, worker morale and productivity will be increased. John (2019) also mentioned that the number of daily commuters will be reduced by $41 \%$ if the workers will be able to work remotely $50 \%$ of their time. However, in Rwanda people who prefer telecommuting have been seen as lazy people or anti-social people (Opobo, 2015). Telecommuting in Rwanda is a bit common among the youth, but it is not popular even people can think that you are rude, or you do not want work if you say that you want to work from home or telecommute which is in line with what R11 said.

R11: "Before COVID that was not here. We used to commute to work! Telecommuting is not common especially in Africa, so Rwanda is not an exception. Even if you tell your worker like I want to work from home, he/she will think that you are rude, or you do not want to work at all”.

However, telecommuting or any other form of having an alternative work schedule was confirmed in many countries as a success story that reduced traffic congestion in their cities. One of the valid examples is an empirical study done in the Netherlands using transportation data from 2000-2016 which showed that without flexible working schedules traffic would be increased by $4 \%$. The same research proved that alternative departure choice reduced traffic during the peak period by $7 \%$. (van der Loop, Rinus, \& Jasper, 2017). This can be emphasized by what R11 mentioned as a moral reason Rwanda can study from COVID 19.

R11: "Another thing that can help is telecommuting because now in corona traffic has reduced! Some workers are working from home. Now the situation is better. Suppose that we are 80 workers where I work and all of us have cars. If 40 works from home means that something can be reduced on traffic. And generally, more cars moving On the road are the main cause of traffic! I think that can be a reason us Rwandan can learn from this period of COVID 19 ".

To summarize this part of the availability of alternative work schedules, it is obvious that workers do not have many alternatives in terms of choosing where to work or when to start or end work. Having the ability to change the location of your workplace does not mean that you are rude or anti-social as some people think. I agree with what R11 mentioned that we can learn from the experience we had in corona to fight traffic congestion in Kigali city. However, the analysis of the availability of work schedules in Kigali city only reflects on questionnaire data, secondary data, 
and 1 interview that was done instead of doing 3 interviews as it was intended. The analysis results also reflect all the 3 selected neighborhoods because working conditions are the same in Rwanda and analyzing each case alone on questionnaire responses did not prove any difference in answers.

\subsubsection{Commuting distance}

Two indicators were used on this sub-variable to know the location of workplaces in Kigali city and to know where workers from Gisozi, Gatenga, and Kimironko works. The first indicator is the location of workplaces whereas the second indicator is the average commuting distance that was computed using google maps to support findings from interviews and questionnaires about the location of workplaces.

\section{Location of workplaces}

The results from interviews show that workplaces are clustered in the same area named CBD which is comprised of 2 places known as Mumugi and Nyabugogo. 7/11 interviews stated that many working places are there because many businesses are located in the CBD. The other 4/11 interviews said that workplaces in Kigali city are located in a different part of the city. However, 91 out of 161 workers said that they work in a CBD. This means that $56.52 \%$ of all workers from the 3 Neighborhoods commute every day to the CBD. In Gisozi neighborhoods $64.7 \%$ of workers work in the CBD, in Kimironko neighborhood $45.45 \%$ of workers work in the CBD, whereas in Gatenga $60 \%$ of workers work in the CBD. The figure 1 below shows the location of the workplace for each neighborhood.

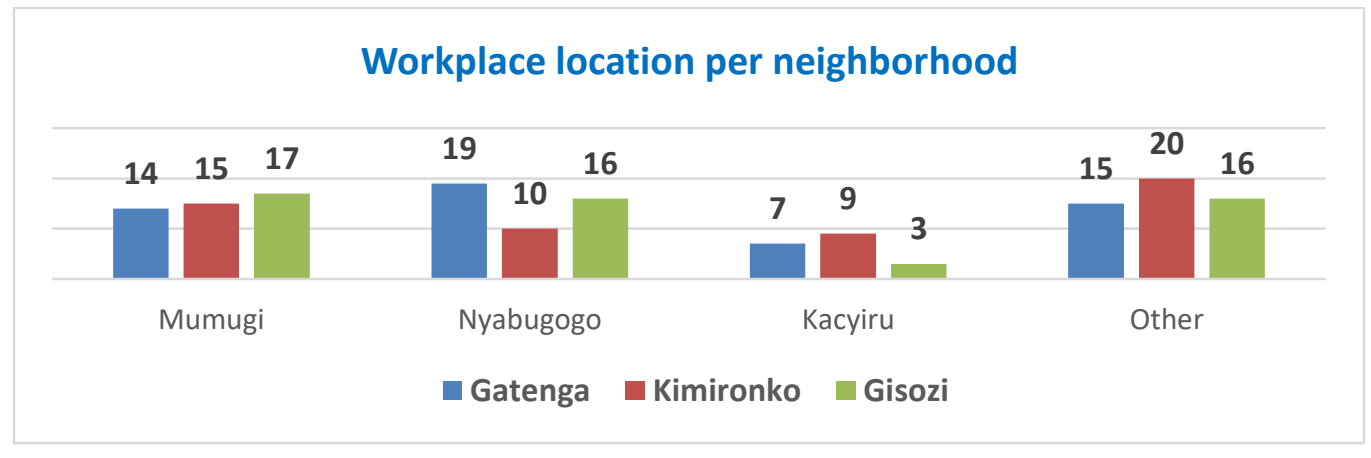

Figure 2: Survey results: workplace location per each neighbourhood 
Rwanda Journal of Engineering, Science, Technology and Environment, Volume 4, Issue 1, June 2021

eISSN: 2617-233X | print ISSN: 2617-2321

Further 10/11 interview pointed out that the distance from residential area to where people work is quite long. The survey result shows that $68.32 \%$ of workers consider the distance from where they work and where they live not far nor near whereas $18.63 \%$ consider the distance to be far.

\section{Average commuting distance}

Kimironko-CBD road average commuting distance is $10.5 \mathrm{~km}$ and Nyanza, Kicukiro-CBD road average commuting distance is $10.8 \mathrm{Km}$. Gisozi-CBD road average commuting distance is $3 \mathrm{~km}$. The average commuting distance was calculated using Google maps taken in the off-peak period (midnight) to explain the reason why people find where they work near or far. Further explanation of workplace location was explained in mixed land use section. According to the above data from the survey, people from Kimironko and Gatenga find their workplace location far compared to workers from Gisozi. The reason why is because there is a short distance from the CBD to Gisozi compared to the other roads (Kimironko-CBD and Nyanza, Kicukiro-CBD).

\subsection{Land use design}

This variable has 2 sub-variables which are connectivity and land use mix. Each sub-variable was analyzed separately where the results of all indicators from interviews were presented first and then supported by findings from questionnaires, ArcGIS, and secondary sources where necessary.

\subsubsection{Connectivity}

The indicators used to explain connectivity include Availability of 3-way and 4-way intersection and roads physical conditions.

\section{Availability of 3-way and 4-way intersection}

Interview respondents could not mention the availability of the intersection of roads without mentioning traffic congestion. One thing that all the interviews pointed is that we have enough intersections of roads in Kigali city however, all of them agreed that they increase traffic because the road width in Kigali is small. To support findings from the interview, ArcGIS pro was used to compute Kernel density that shows the concentration or density of features around a point, or a line was used. In this case, the main roads under the study were used together with the road intersections. The following figure 2 shows Kernel density results. 


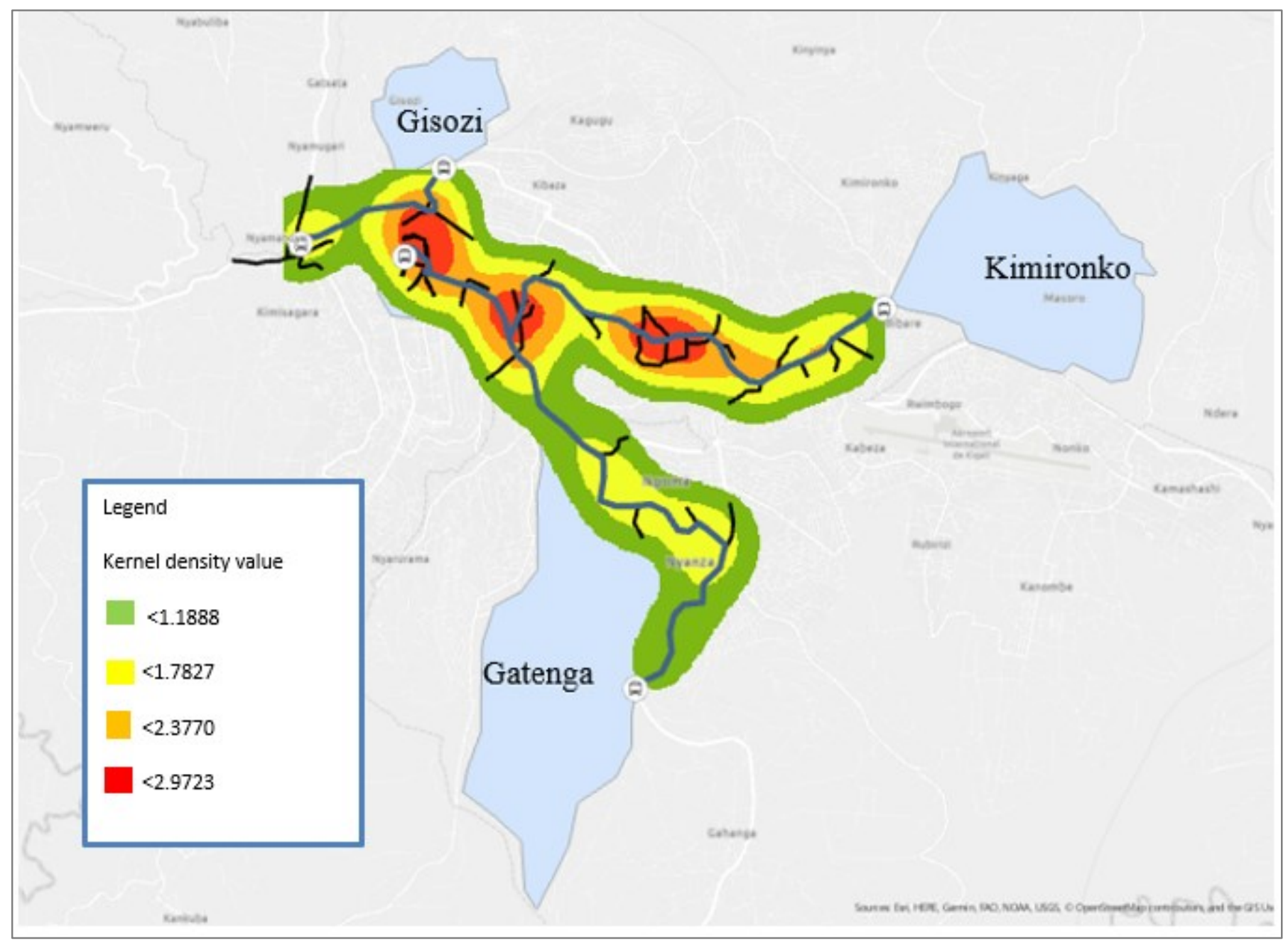

\section{Figure 3: Kernel analysis of intersection points}

The results from ArcGIS show that there is a high concentration of roads in the CBD, Kacyiru, and where the 2 main roads under this study meet. The overall availability of 3- and 4-way intersections is high because where the main roads meet with the other roads have a high density shown in red color.

\section{Roads physical conditions}

Only 1/11 interview mentioned that "the roads in Kigali are good compared on the normal standard of the roads". The other 10/11 interviews stated that roads in Kigali city are small in width where many are one lane. The interviews also mentioned that the roads are few which was also on top of the causes of traffic congestion in Kigali city. However, those answers were made 
from 11 interviews out of 16 that were intended to be done. Probably more supporting arguments about having better roads in Kigali city would have appeared. The fact that roads are few was emphasized from the survey findings where only 2 respondents from the entire study area mentioned that in their daily trips to work, they do not use any the of roads disclosed in this study. This means that even if only $56.52 \%$ of the respondents work in the CBD, $98.76 \%$ of all the workers use the roads connecting Gatenga, Kimironko, and Gisozi neighborhoods to the CBD.

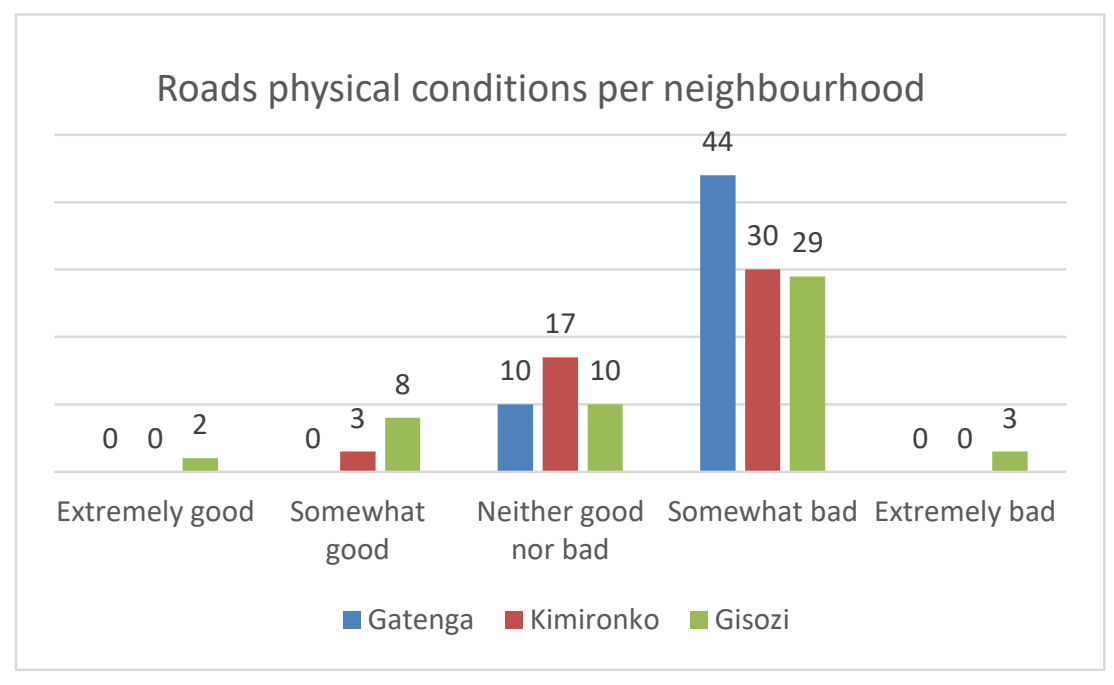

\section{Figure 4: Survey results: Roads physical conditions per Neighborhood}

The survey data corrected on each neighborhood shows that Kimironko-CBD road is somewhat better compared to the other roads. This assumption was made based on the distribution of responses in figure 5. The road Nyanza, Kicukiro-CBD was considered as the second one which is better among the 3, whereas Gisozi- CBD road was considered as the last one because $66.6 \%$ of the respondents said that it is somewhat bad and extremely bad.

\subsubsection{Land use mix}

The sub-variable has one indicator which is the availability of land use mix plans that was later supported by the answers collected in a survey about the availability of workplaces in the neighborhood. 
Rwanda Journal of Engineering, Science, Technology and Environment, Volume 4, Issue 1, June 2021

eISSN: 2617-233X | print ISSN: 2617-2321

\section{Availability of land use mix plans}

Two urban planners that were interviewed agreed that they are workplaces within the residential area. One emphasized that the masterplan of the city support land use mix of residential area and workplaces, however, another one mentioned that even if the workplaces are there, they are not many to accommodate the entire neighborhood working group. out of curiosity the other question asking whether Kigali city can be considered as a centrally planned city, 7/11 respondents mentioned that the $\mathrm{CBD}$ is more developed than the other area and they mentioned that there are more workplaces in the CBD than in the other parts of the city. This can be proved by the survey data presented before showing that $56.52 \%$ of all workers work in the CBD. The survey data was conducted about the availability of workplaces like schools, shopping centers, hospitals, and offices in Gisozi, Kimironko and Gatenga neighborhood and as the result shows many agreed that those workplaces are there. The distance from the workplaces to neighborhood was also asked where many workers said that workplaces are within $2 \mathrm{Km}$ of where they live.

Secondary data from Kigali city masterplan 2013 shows the plan supports mixed land use of residential with workplaces at the neighborhood level in General. This is similar to the findings from the interview where R7 said: "Every zoning plan of any district of Kigali City supports land use mix of residential areas and workplaces in Kigali city. They are all available online at 2013 Kigali Master Plan online platform". However, The CBD of this study which is composed of Nyabugogo and Mumugi has more commercial areas than the neighborhoods. This explains the reason why many workers go to work in the CBD. It also emphasizes the fact that 7/11 interviews stated that many workplaces are found in the CBD in Kigali city. The maps below were extracted from Kigali city master plan 2013 and shows why many workers work in the CBD rather than in their neighborhood. 


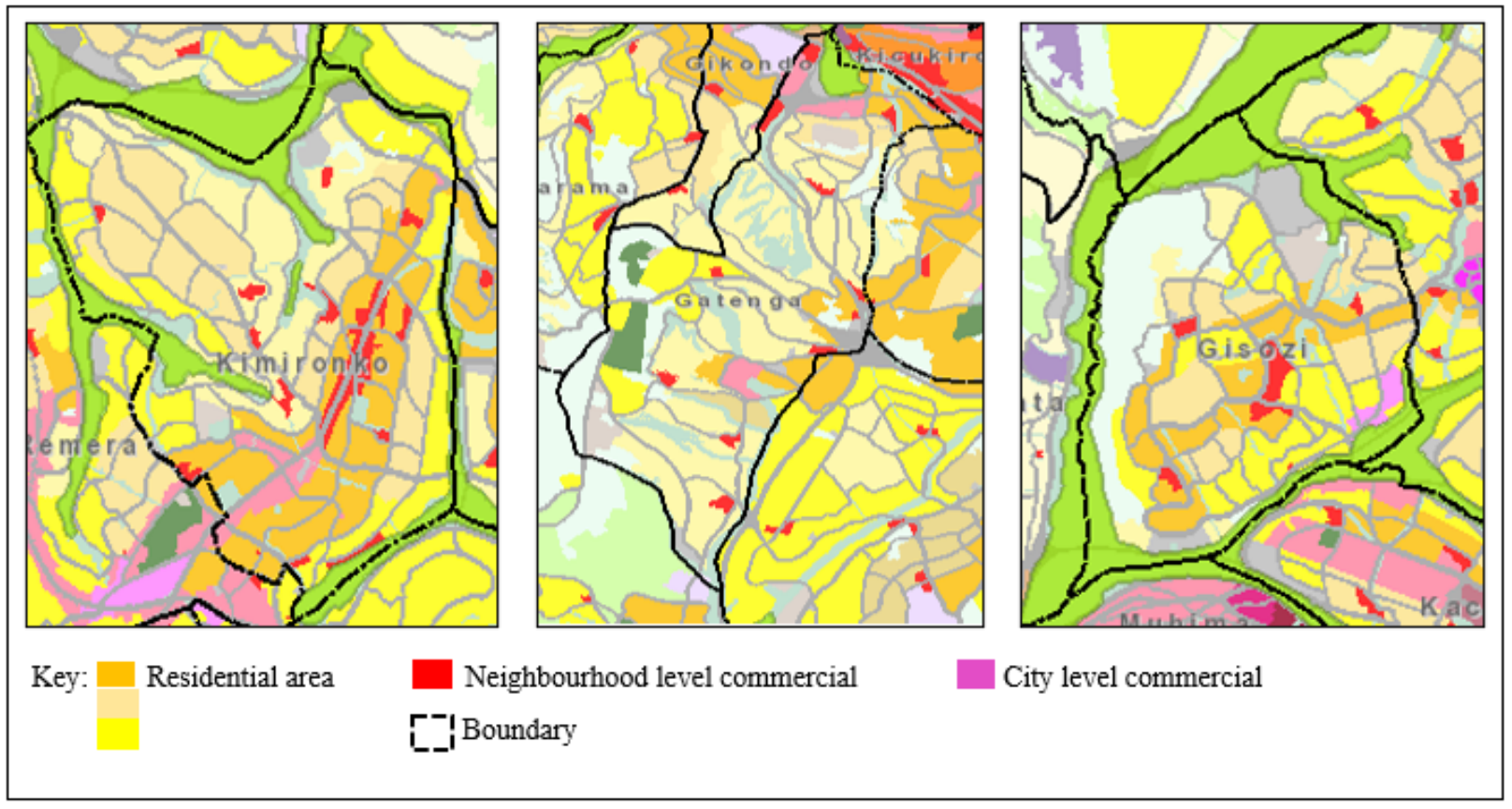

Figure 5: Kimironko, Gatenga, and Gisozi land use

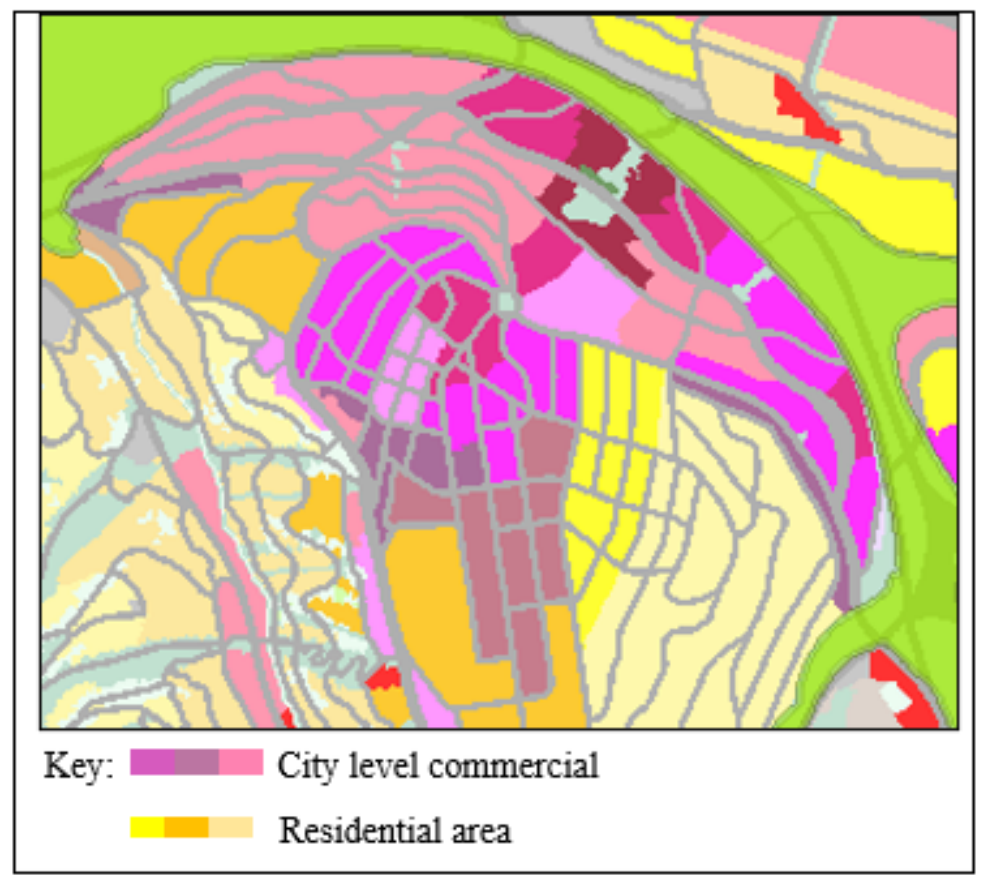

Figure 6: CBD Land Use

Source: https://masterplan2020.kigalicity.gov.rw 
Rwanda Journal of Engineering, Science, Technology and Environment, Volume 4, Issue 1, June 2021

eISSN: 2617-233X | print ISSN: 2617-2321

To sum up this section of mixed land use availability, they are workplaces within the residential area as supported by Kigali city masterplan. The workplaces are distributed equally in all neighborhoods and they are located not far away from the residential area. However, the available workplaces within neighborhoods are not enough to cope with the number of workers in that neighborhood. The fact that the CBD is more developed than the other area attracts more than half of the workers in the 3 neighborhoods.

\subsection{Traffic congestion}

This variable has two sub-variables which are travel time and level of service.

\subsubsection{Travel time}

In this study, travel time was measured using the data for the peak period and off-peak period.

\section{Average travel time in peak-period}

Travel time and mode of transport a commuter use to move from one place to another are related. The survey data collected showed that the modes of transport used to go and come back from work are the same. The figure 4 shows the relationship between travel time in the peak period by different modes of transport. 

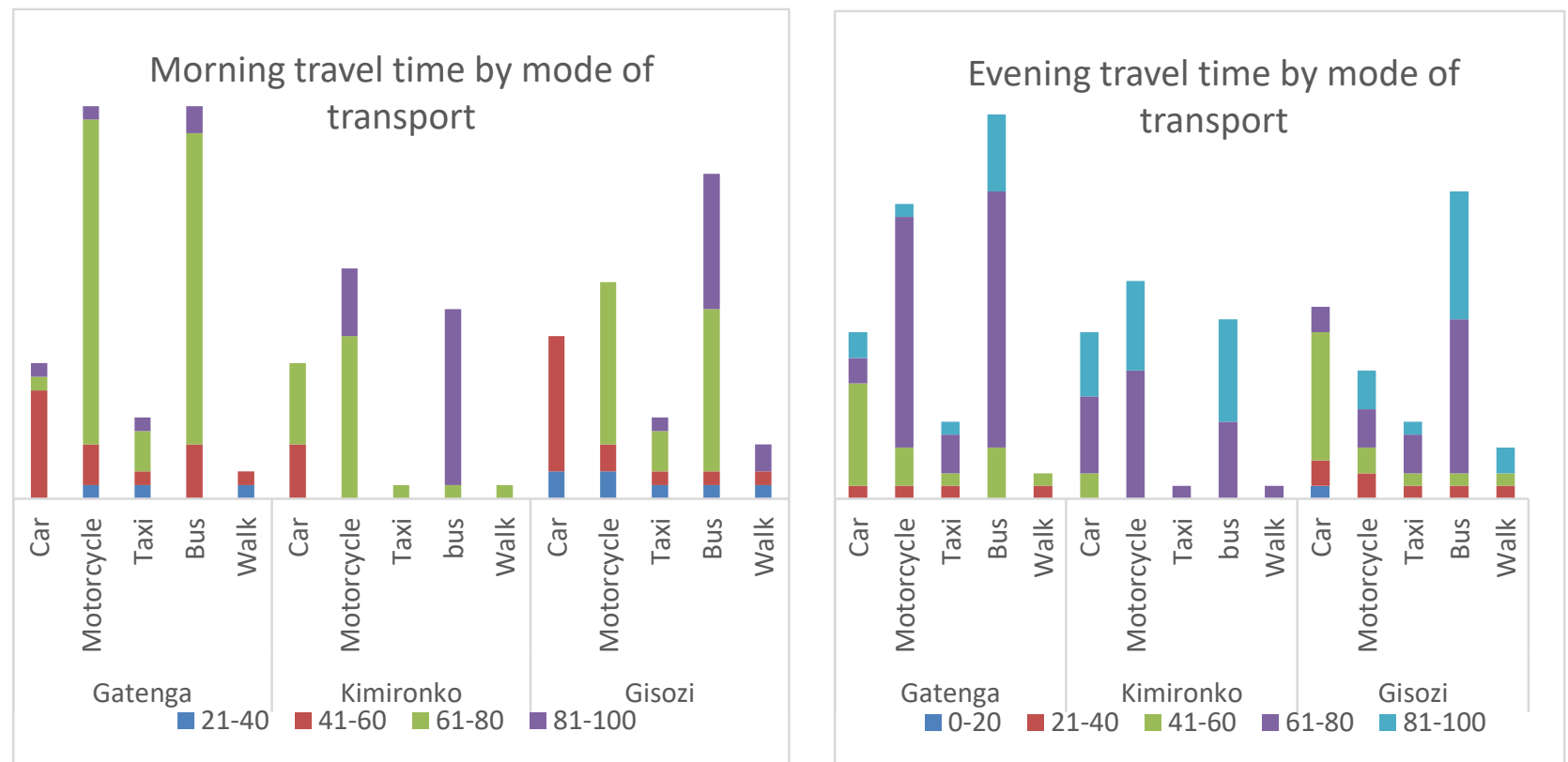

Figure 7: Survey results: Travel time in peak period (morning and evening) by mode of transport

\section{Average time travelled in off-peak period.}

One interviewee from the transportation sector pointed out that travel time in the off-peak period is lower compared to the peak-period. The survey data collected showed that most of the workers travel during peak period. To get off-peak period travel time, secondary data source of google maps was used.

Table 3: Average travel time per mode of transport in off-peak period

\begin{tabular}{|l|l|l|}
\hline Road & Off- peak period \\
\cline { 2 - 3 } & Car & Bus \\
\hline Kimironko-CBD & 18 minutes & 47 minutes \\
\hline Nyanza, Kicukiro-CBD & 20 minutes & 50 minutes \\
\hline Gisozi-CBD & 6 minutes & 10 minutes \\
\hline
\end{tabular}


Travel time in peak period is higher than travel time in off-peak period. Additionally, travel time and mode of transport are associated. Only 3.98\% of all workers said that the walk from home to workplace. This means that the commuting distance from where they work and where they live is not short. That is why $42.55 \%$ of workers use buses, $5.17 \%$ of workers use taxi, $31.61 \%$ of workers use motorcycles whereas $16.72 \%$ of workers use cars. This was explained further in the previous section of land use mix.

\subsubsection{Level of service}

This sub-variable has one indicator which is average vehicle speed. The average vehicle speed was used to determine which level of service belongs to each road using distance and travel time measures presented in the sections above. The level of service ranges from $\mathrm{A}$ to $\mathrm{F}$ based on different factors.

Table 4: Average speed in off-peak period and peak period

\begin{tabular}{|c|c|c|c|c|c|c|c|c|c|}
\hline \multirow[t]{2}{*}{ Road } & \multirow[t]{2}{*}{$\begin{array}{l}\text { dista } \\
\text { nce }\end{array}$} & \multicolumn{2}{|c|}{$\begin{array}{l}\text { Travel time } \\
\text { in off-peak } \\
\text { period }\end{array}$} & \multicolumn{2}{|c|}{$\begin{array}{l}\text { Speed in off- } \\
\text { peak period }\end{array}$} & \multicolumn{2}{|c|}{$\begin{array}{l}\text { Travel time } \\
\text { in peak } \\
\text { period }\end{array}$} & \multicolumn{2}{|c|}{$\begin{array}{l}\text { Speed in peak- } \\
\text { period }\end{array}$} \\
\hline & & Car & Bus & Car & Bus & Car & Bus & Car & Bus \\
\hline Kimironko-CBD & $\begin{array}{l}10.5 \\
\mathrm{Km}\end{array}$ & $\begin{array}{l}18 \\
\min \end{array}$ & $\begin{array}{l}47 \\
\min \end{array}$ & $\begin{array}{l}35 \\
\mathrm{Km} / \mathrm{h}\end{array}$ & $\begin{array}{l}13.5 \\
\mathrm{~km} / \mathrm{h}\end{array}$ & $\begin{array}{l}62 \\
\min \end{array}$ & $\begin{array}{l}79 \\
\min \end{array}$ & $\begin{array}{l}10.1 \\
\mathrm{Km} / \mathrm{h}\end{array}$ & $8.01 \mathrm{Km} / \mathrm{h}$ \\
\hline $\begin{array}{l}\text { Nyanza, } \\
\text { Kicukiro-CBD }\end{array}$ & $\begin{array}{l}10.8 \\
\mathrm{Km}\end{array}$ & $\begin{array}{l}20 \\
\min \end{array}$ & $\begin{array}{l}50 \\
\min \end{array}$ & $\begin{array}{l}33 \\
\mathrm{Km} / \mathrm{h}\end{array}$ & $\begin{array}{l}13.0 \\
\mathrm{~km} / \mathrm{h}\end{array}$ & $\begin{array}{l}57 \\
\min \end{array}$ & $\begin{array}{l}69 \\
\min \end{array}$ & $\begin{array}{l}11.3 \\
\mathrm{Km} / \mathrm{h}\end{array}$ & $9.39 \mathrm{Km} / \mathrm{h}$ \\
\hline Gisozi-CBD & $3 \mathrm{Km}$ & $\begin{array}{l}6 \\
\min \end{array}$ & $\begin{array}{l}10 \\
\min \end{array}$ & $\begin{array}{l}30 \\
\mathrm{Km} / \mathrm{h}\end{array}$ & $\begin{array}{l}19 \\
\mathrm{Km} / \mathrm{h}\end{array}$ & $\begin{array}{l}49 \\
\min \end{array}$ & $\begin{array}{l}73 \\
\min \end{array}$ & $\begin{array}{l}3.7 \\
\mathrm{Km} / \mathrm{h}\end{array}$ & $2.47 \mathrm{Km} / \mathrm{h}$ \\
\hline
\end{tabular}

By comparing the speed of buses and cars in peak-period, the difference is not higher as it is perceived in off peak period. Speed was used in this study to measure the level of service because speed explains the reduction in mobility commuters' experience in traffic congestion. 
Rwanda Journal of Engineering, Science, Technology and Environment, Volume 4, Issue 1, June 2021

eISSN: 2617-233X | print ISSN: 2617-2321

\section{$\underline{\text { Level of service Kimironko CBD road }}$}

Based on the speed experienced by vehicles in peak period the road is classified under level E. this means that there is an unstable flow of vehicles during peak periods where the average vehicle per capacity is $91 \%-100 \%$.

\section{$\underline{\text { Level of service Nyanza, Kicukiro- CBD road }}$}

Based on the speed results of buses and cars in peak period the road is classified under level E. this means that there is an unstable flow of vehicles during peak periods where the average vehicle per capacity is $91 \%-100 \%$.

\section{$\underline{\text { Level of service Gisozi- CBD road }}$}

Based on the speed results of buses and cars in peak period the road is classified under level F. this means that there is forced flow of vehicles during peak periods where the average vehicle per capacity exceeds $100 \%$. This can be emphasized by the fact that physical conditions of this road are not good comparing to the other roads.

However, to compare peak period and off-peak period travel time and speed, the speed reduction index (SRI) was used. SRI means the relative speed change between free-flow and congested conditions which range from 0-10. Congestion occurs when SRI exceeds 5. Values of less than 4 means that there is no congestion (Wallin, 2020) The Speed Reduction formula is:

$\mathrm{SRI}=\left(1-\mathrm{V}_{\mathrm{ac}} / \mathrm{V}_{\mathrm{ff}}\right) \times 10$, where $\mathrm{V}_{\mathrm{ac}}$ is the actual travel speed and $\mathrm{V}_{\mathrm{ff}}$ is the free flow speed or off-peak period speed as named by (Wallin, 2020).

Using the above SRI formula on the results provided in table 4, SRI of Kimironko-CBD road is 6.3, SRI of Nyanza, Kicukiro-CBD road is 5.6 and SRI of Gisozi CBD road is 8.7. The results show that all the roads have SRI which is higher than 5 which means that the roads are congested.

However, the results show that Gisozi-CBD road is the most congested road regardless the fact that this road is the shortest among the others. Based on the above-mentioned indicators in different sections of this chapter, the reason behind this is because the road physical conditions are bad 
compared to other roads. Additionally, the road has 4- or 3-way intersections which increases vehicles queues because many cars meet at the small width of the road.

\subsection{Statistical results}

The table 5 below shows the correlation results for the entire study area between travel time as the dependent variable and independent variables that were statistically significant among the others as presented in Annex 4. Both morning and evening travel time gave the same results hence only morning travel time results were presented to avoid repetition. Only working trips from the 3 residential areas (Gisozi, Gatenga, Kimironko) to the CBD were considered.

Table 5: Spearman's correlation results for the entire study

\begin{tabular}{|l|l|}
\hline & Travel Time \\
\hline Commuting distance & $.249^{*}$ \\
\hline Time to reach home from work & $.285^{*}$ \\
\hline Vehicle occupancy & $.214^{*}$ \\
\hline
\end{tabular}

*Correlation is significant at the 0.05 level (2-tailed)

The spearman's correlation results show that there is a positive correlation only between travel time, commuting distance, vehicle occupancy and time to reach home from work. However, the relationship between commuting distances is weak but as explained above commuting distance and travel time are highly related in off-peak period. Time to reach home from work and travel time are positively correlated but the relationship is weak. This means that as you use few minutes to travel, you will reach your home early. This relationship is true however, the correlation is weak because the data collected are for workers who moves in peak period. This means that workers spend long time on the road which has little impact on the time they reach their home. Another correlation observed is between vehicle occupancy and travel time. This means that people who have their cars or motorcycles travel less than people who use buses. However, the relationship is weak in peak period compared to the off-peak period. This means that in Peak-period whether you use a car or bus the difference in travel time is short because all the vehicles are queuing together. 
The difference in travel time between cars and bus in peak period occurs when a bus stop to pick up passengers.

The causal relationship between the dependent and independent variables of questionnaire data was carried out using ordinal regression since the dependent variable is ordinal and the independent variables are classified under ordinal category. Travel time was analyzed as independent variable, whereas commuting distance, vehicle occupancy and time to reach home from work were analyzed as independent variables. The results of the regression analysis show that there is a significant fitting in the final modal of ordinal regression between travel time with commuting distance, vehicle occupancy and time to reach home from work as the final significant is 0.000 which is less than $\mathrm{P}=5 \%$.

Table 6: SPSS Model fitting information

Model Fitting Information

\begin{tabular}{|l|r|r|r|r|}
\hline Model & \multicolumn{1}{|c|}{$\begin{array}{c}-2 \text { Log } \\
\text { Likelihood }\end{array}$} & Chi-Square & df & Sig. \\
\hline Intercept Only & 96.090 & & & \\
Final & 72.115 & 23.975 & 3 & .000 \\
\hline
\end{tabular}

The ordinal regression model for the entire study area shows that the 3 independent variables which are commuting distance, time to reach home from work, and vehicle occupancy are statistically significant with travel time as their P value is less than 5\%. However, the other indicators which were not statistically significant in correlation test were not included in the modal. Only statistically significant indicators were used to test their influence on travel time as shown in Table 7 below. 
Rwanda Journal of Engineering, Science, Technology and Environment, Volume 4, Issue 1, June 2021

eISSN: 2617-233X | print ISSN: 2617-2321

Table 7: SPSS ordinal regression model for the entire study results

\begin{tabular}{|c|c|c|c|c|c|c|c|c|}
\hline \multicolumn{9}{|c|}{ Parameter Estimates } \\
\hline & & \multirow[b]{2}{*}{ Estimate } & \multirow[b]{2}{*}{ Std. Error } & \multirow[b]{2}{*}{ Wald } & \multirow[b]{2}{*}{ df } & \multirow[b]{2}{*}{ Sig. } & \multicolumn{2}{|c|}{$95 \%$ Confidence Interval } \\
\hline & & & & & & & Lower Bound & Upper Bound \\
\hline \multirow[t]{3}{*}{ Threshold } & [Traveltime $=1$ ] & 7.008 & 1.945 & 12.990 & 1 & .000 & 3.197 & 10.820 \\
\hline & [Traveltime = 2] & 7.942 & 1.975 & 16.165 & 1 & .000 & 4.070 & 11.813 \\
\hline & [Traveltime = 3] & 11.512 & 2.205 & 27.265 & 1 & .000 & 7.191 & 15.833 \\
\hline \multirow[t]{3}{*}{ Location } & Distance & 1.569 & .422 & 13.796 & 1 & .000 & .741 & 2.397 \\
\hline & Time_To_Reach_Home & 1.045 & .393 & 7.085 & 1 & .008 & .276 & 1.815 \\
\hline & Vehicle_occupancy & 1.366 & .432 & 9.996 & 1 & .002 & .519 & 2.212 \\
\hline
\end{tabular}

Link function: Logit.

The statistical test for the entire study shows that there is only a significant relationship between commuting distance, vehicle occupancy, and time to reach home from work and travel time while other factors like physical conditions and departure time do not matter in influencing travel time. However, Cronbach $\alpha$ test shows that there is good reliability of indicators within each variable and secondary data sources of off-peak period proved that there is a strong correlation between travel time and different indicators. Additionally, it was presented before in the interview findings and literature that there is a significant relationship between inflexible work schedules, land use design and traffic congestion. Based on the above-mentioned reasons, the researcher does not agree with these results because the data collected were for workers who commute in peak period hence some indicators that can increase or reduce travel time were not all statistically significant.

\section{Discussion and conclusions}

\subsection{Discussion}

\subsubsection{Departure Time Choice and Commuting Distance as Inflexible Work}

\section{Schedules}

The results show that workers to a high extent do have alternatives to choose where to work or when to start and end work, which supports the argument by Lundqvist, (2003), that inflexible working schedules that do not allow people to choose when and where to work have proven to hinder the environmental, social, and economic effects of congestion. This challenge is also attributed to the administrative function of Kigali city, which is centrally planned, encouraging people to live far from their place of work, which is in the city center and not close to their residential areas, thus leads to more inflexible working schedules and increased average 
Rwanda Journal of Engineering, Science, Technology and Environment, Volume 4, Issue 1, June 2021

eISSN: 2617-233X | print ISSN: 2617-2321

commuting distance (Meerkerk, 2015), such as the Kimironko to CBD road (10.5 km) and Nyanza, Kicukiro to CBD $(10.8 \mathrm{~km})$.

\subsubsection{Connectivity and Land-use Mix in Land-use Design.}

The 3-way and 4-way intersection are adequate from the findings; however, its width is inadequate, considering the high volume of cars moving per day from their places of residence and far into the city center, causing traffic congestion. This high concentration at intersections (points), were also affirmed through the kernel density results as concentration of densities of features around a point or lines within the intersections. On the average the roads physical conditions are good, however more routes are required to decentralize the traffic congestion, to allow commuters have more route options leading to the city center. Policies should be incorporated into the masterplan to foster the development of more work-related buildings, as the present master plan does not show enough workplaces close to the residential, as some officially allocated mixed land-use shows that the residential areas have inadequate allocated spaces for commercial and administrative zones close to it. As the CBD is more developed than the other areas, which attracts more than half of the workers in the three neighborhoods. This is against the arguments of Frank (2006) and Meerkerk (2015), whose scholarly work using the mixed land use concept was proved using empirical studies that it mixed land-use contributes to the sustainability of cities. In this regard, Kigali and other cities with similar challenges should provide strict adherence to mixed land-use in the master plan.

To sum up this section of mixed land use availability, they are workplaces within the residential area as supported by Kigali city masterplan. The workplaces are distributed equally in all neighborhoods, and they are located not far away from the residential area. However, the available workplaces within neighborhoods are not enough to cope with the number of workers in that neighborhood. The fact that the CBD is more developed than the other area attracts more than half of the workers in the 3 neighborhoods.

\subsubsection{Travel time and Level of Service during Traffic Congestion}

Travel time in peak period is higher than travel time in off-peak period. Thus, there is less congestion during the off-peak hours, and some respondents affirmed that they prefer to travel 
during the off-peak hours to avoid traffic congestion, which can be inconvenient, especially to big family sizes with limited transport options.

In addition, Leopold (2018) mentioned that many paved roads in Kigali city are in poor conditions because of poor maintenance hence need rehabilitation. This poor maintenance, which depicts poor physical conditions and connectivity issues also contributes to traffic congestion, because sometimes drivers tend to avoid potholes on the roads and in this manner use illegal lanes of the road, which leads to irregularities in driving patterns and consequently to traffic congestion.

\subsubsection{Theoretical and practical relevance of the research}

Kigali city, as the fastest growing city in Africa, needs innovative measures to regulate the transport sector. The sector faces challenges which affect the city development and liveability.

As for theoretical relevance, first of all this is the first study in Rwanda that explains how inflexible work schedules and land use design influence traffic congestion. This study fills a unique gap in literature especially in sub-Saharan Africa. However, there is no empirical research in other countries that combined both inflexible work schedules and land use design as the variables contributing to traffic congestion. All the literatures presented one variable as the main cause of traffic congestion. Secondly, previous studies have shown that inadequate public transport is the major cause of traffic congestion in Kigali city and suggests different solutions including upgrading roads, proposing aerial cable cars and use of electric cars (Leopold and Aloys, 2018). Almost all the proposed measures of traffic congestion want to regulate the supply side of the problem which is not cost effective. In this study, land use design and inflexible work schedules aim to explain the demand side of traffic congestion which can be regulated with no extra cost. Lastly, the finding of this study will be helpful to transport sector, health sector, workers sector and planning sector in Kigali city. This will create a collaboration between those sectors in future planning of secondary cities.

As for societal or practical relevance, this research addresses a need for effective transport which is well managed. Therefore, by resolving the traffic congestion problem they will be a need for mixing land use and introducing flexible work schedules. Besides, they will be a need to integrate workplaces and residential area in the society which can increase productivity and social welfare. 
Within this study, recommendations can be made to the transport sector, health sector, urban planners, decision makers, and the Ministry of workers in Rwanda through improving Kigali city liveability or through developing secondary cities which are new developing cities. Apart from this, the study will provide empirical literature for the next studies by adopting land use design and inflexible work schedules variables that has not yet studied together or by using the other travel demand management variables in explaining traffic congestion issues in developing cities.

\subsection{Conclusions}

To conclude the findings of this study, independent variables inflexible work schedules and land use design have significantly influenced the dependent variable traffic congestion. Traffic congestion only occurs in the peak period when workers are going or coming from work because of inflexible work schedules in Kigali city. Also, roads under this study are congested at different levels due to land use design measurements like connectivity and land use mix. While the results are statistically insignificant due to the small sample size and the representation of the peak period situation only, they match with the findings from secondary data, questionnaires, ArcGIS, and interviews.

Resolving traffic congestion by regulating the supply side will not stop the problem from emerging that is why traffic congestion in Kigali city will continue to increase in the future if the demand side is not controlled. Some of the travel demand management that can help Kigali city to fight traffic includes alternative work schedules and land use design as this study proved. Parking management, public transport efficiency, and promoting car sharing or carpooling also can improve urban mobility. To sum up, boosting urban liveability entails "focusing on the movement of people and goods rather than the movement of vehicles" (Ferguson, 2016,p.9).

\section{References}

Atomode, T. I. (2012). Traffic congestion at road intersections in ilorin, nigeria doi:10.5901/mjss. 2012.v3n2.201

Dan, N. (2017, ). Nyabugogo - gatsata road expansion starts. KTpress Retrieved from https://www.ktpress.rw/2017/05/nyabugogo-gatsata-road-expansion-starts/ 
Rwanda Journal of Engineering, Science, Technology and Environment, Volume 4, Issue 1, June 2021

eISSN: 2617-233X | print ISSN: 2617-2321

Daniel, B., Manfred, B., \& Felix, C. (2010). Beyond the fossil city: Towards low carbon transport and green growth. Germany: Deutsche Gesellschaft für Technische Zusammenarbeit (GTZ) GmbH.

Daragay, J. (2003). The impact of land use patterns on travel behaviour

Ferguson, E. (2016). Transportation demand management planning, development, and implementation. Journal of the American Planning Association, 56(4), 442-456. doi:10.1080/01944369008975448

Fortune of Africa. (2014). Working hours and holidays in rwanda. Retrieved from https://fortuneofafrica.com/rwanda/working-hours-and-holidays/

Frank, L. D. (2006). Impacts of mixed land use and density on utilization of three modes of travel: Single occupancy vehicle, transit and walking Arizona Republic (1930 - 2007), 117(76), 66. Retrieved from https://search.proquest.com/docview/1941957964

Hirshfield, J. (2019). Flexible work hours World Literature Today, 93(3), 59.

Jabareen, Y. R. (2006). Sustainable urban forms. Journal of Planning Education and Research, 26(1), 38-52. doi:10.1177/0739456X05285119

Janssen, N. (2017). An empirical study on the relationship between commuting distance and job satisfaction

Jean Chrétien, M. (2017). "Traffic jam in kigali city: Causes, effects and preventive strategies". case study: Kigali city

John, L. H. (2019). Flexible working, the neglected congestion-busting solution for our cities. Retrieved from https://theconversation.com/flexible-working-the-neglected-congestionbusting-solution-for-our-cities-122130

Leopold, M., \& Aloys, D. (2018). Proposal of aerial cable car as an alternative means of public transport in kigali city

Lundqvist, L. (2003). Land-use and travel behaviour. A survey of some analysis and policy perspectives. European Journal of Transport and Infrastructure Research, 3(3) doi:10.18757/ejtir.2003.3.3.4243

Meerkerk, R. v. (2015). Mixed Land Use in the Urban Environment - Exploring the impact of physical diversity on residential property prices in Rotterdam.

Ministry of Infrastructure. (2008). Rwanda transport sector review and action plan 
Rwanda Journal of Engineering, Science, Technology and Environment, Volume 4, Issue 1, June 2021

eISSN: 2617-233X | print ISSN: 2617-2321

Monowar, M., Mohammad, A. b. \& Salma, A. (2009). Traffic management system and travel demand management (TDM) strategies: Suggestions for urban cities in bangladesh. Retrieved from http://asiair.asia.edu.tw/ir/handle/310904400/9407

National Institute of statistics of Rwanda. (2015). Population size, structure and distribution Republic of Rwanda. Retrieved from https://search.credoreference.com/content/entry/ngeolgpf/rwanda_republic_of_rwanda/0 Observers. (2015). Bus modernisation drives kigali residents to 'despair'. France 24 Retrieved from https://observers.france24.com/en/20150216-kigali-bus-users-modernisation-plan

Omondi, A. (2018). Flexible work schedules: A critical review of literatures

Opobo, M. (2015). Telecommuting is the new order of work. New Times, Retrieved from https://www.newtimes.co.rw/section/read/187341

Parthasarathi, P., Levinson, D., \& Hochmair, H. (2013). Network structure and travel time perception. PloS One, 8(10), e77718. doi: 10.1371/journal.pone.0077718

Republic of Rwanda. (2009). Labour law of rwanda. Retrieved from http://www.primature.gov.rw/index.php?option=com_docman\&task=cat_view\&gid=39\& Itemid $=95$

Saelens, B., Sallis, J., \& Frank, L. (2003). Environmental correlates of walking and cycling: Findings from the transportation, urban design, and planning literatures. Annals of Behavioral Medicine, 25(2), 80-91. doi:10.1207/S15324796ABM2502_03

Saleh, W., \& Farrell, S. (2005). Implications of congestion charging for departure time choice: Work and non-work schedule flexibility. Transportation Research Part A, 39(7), 773-791. doi: $10.1016 /$ j.tra.2005.02.016

Stangl, P., \& Guinn, J. M. (2011). Neighborhood design, connectivity assessment and obstruction. URBAN DESIGN International, 16(4), 285-296. doi:10.1057/udi.2011.14 statistics solution. (2015). Qualitative sample size. Retrieved from https://www.statisticssolutions.com/qualitative-sample-size/

van der Loop, H., Rinus, H., \& Jasper, W. (2017). The impact of various forms of flexible working on mobility and congestion estimated empirically KiM Netherlands Institute for Transport Policy Analysis. 
Rwanda Journal of Engineering, Science, Technology and Environment, Volume 4, Issue 1, June 2021

eISSN: 2617-233X | print ISSN: 2617-2321

Wallin, M. (2020). Traffic data, route planning, and ETA: How google maps predict travel time. Retrieved from https://www.verizonconnect.com/resources/article/google-maps-traveltime/\#: :text=GPS\%20data\%20from\%20individual\%20phones,speed\%20when \%20condi tions $\% 20$ are $\% 20$ clear.

World Bank Group. (2018). Urban transport infrastructure and household welfare evidence from Colombia

Yu, R., Burke, M., \& Raad, N. (2019). Exploring impact of future flexible working model evolution on urban environment, economy and planning. Journal of Urban Management, 8(3), 447-457. doi: 10.1016/j.jum.2019.05.002 